\author{
بررسى نقش تنظيم كنندههاى رشد و نور بر ميزان فنول و باززايى آلوئه ورا

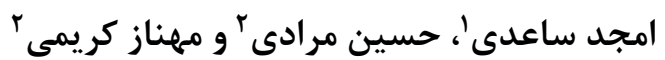

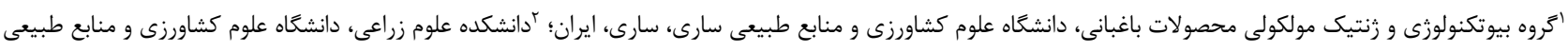 \\ سارى، سارى، ايران \\ مسؤول مكاتبات: حسين مرادى، h.moradi@sanru.ac.ir
}

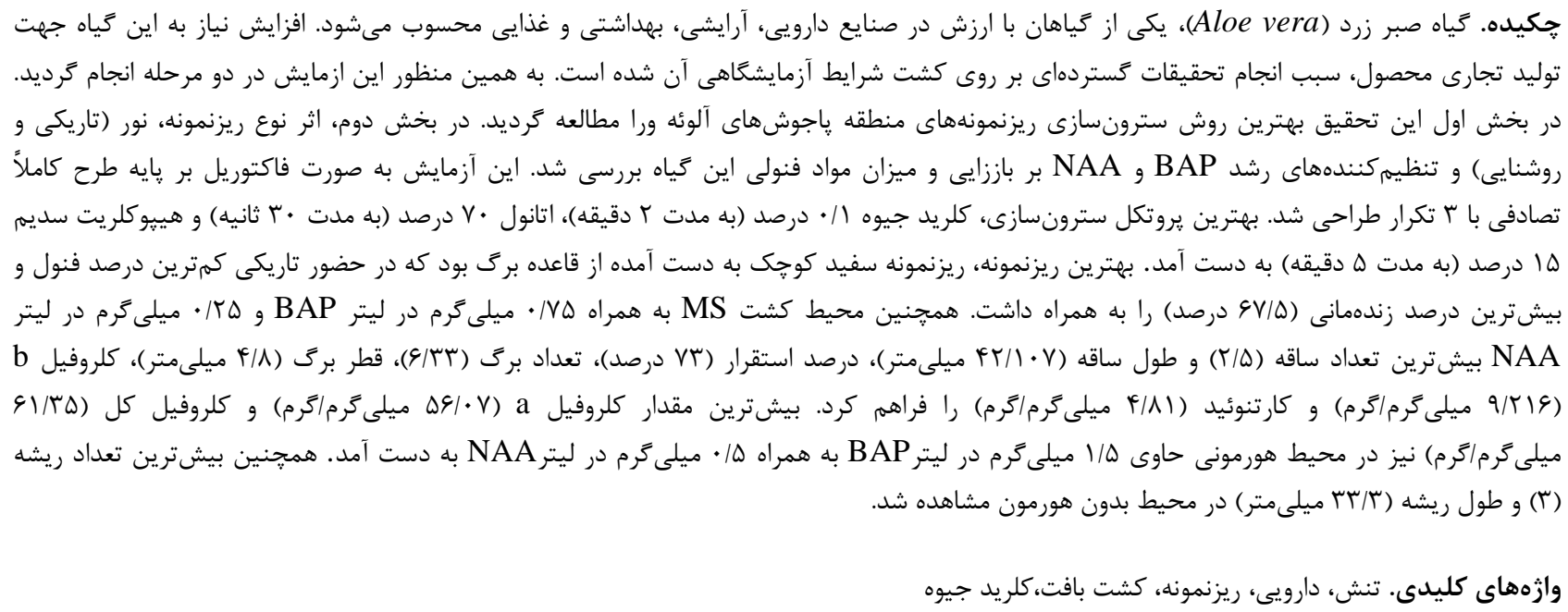

\title{
The effect of growth regulators and light on the phenolic content and in vitro regeneration of Aloe vera
}

\author{
Amjad Saedi' ${ }^{1}$, Hossein Moradi $^{2}$ \& Mahnaz Karimi ${ }^{2}$ \\ ${ }^{1}$ Biotechnology and Genetics of Molecular Horticulture Products, Sari Agricultural Sciences and Natural Resources \\ University (SANRU), Sari, Iran; ${ }^{2}$ Faculty of Crop Sciences, Sari Agricultural Sciences and Natural Resources \\ University (SANRU), Sari, Iran \\ Correspondent author: Hossein Moradi, h.moradi@sanru.ac.ir
}

\begin{abstract}
Aloe vera L. is one of the most valuable plants in the pharmaceutical, cosmetic, sanitary and food industries. In vitro culture is used for commercial production and due to the abundant application of this plant, extensive research has been performed on the in vitro culture of Aloe vera. For this purpose, the present study was conducted at two stages . At the first stage, the best method of sterilization of explants derived from Aloe vera offshoots was investigated. At the second stage, the effect of the type of explants, the light condition (dark and bright) and the effect of BAP (Benzyl Amino Purine) and NAA ( $\alpha$-Naphthalene acetic acid)) growth regulators on regeneration and the amount of phenolic compounds were studied. A factorial experiment was executed on the basis of a completely randomized design with three replications. The best sterilization protocol was $0.1 \%$ mercuric chloride (for 2 minutes), $70 \%$ ethanol (for 30 seconds) and $15 \%$ sodium hypochlorite (for 5 minutes). The little white explant derived from the base of leaves, with the lowest percentage of phenol and the highest survival rate $(67.5 \%)$ in darkness, was found to be the best candidate. MS medium supplemented with $0.75 \mathrm{mg} / \mathrm{L}$ BAP and $0.25 \mathrm{mg} / \mathrm{L}$ NAA resulted in the highest stem number (2.5) and stem length $(42.107 \mathrm{~mm})$, establishment percentage (73\%), leaf number (6.33), leaf diameter $(4.8 \mathrm{~mm})$, chlorophyll b $(9.216 \mathrm{mg} / \mathrm{g})$ and carotenoids $(4.81 \mathrm{mg} / \mathrm{g})$. The highest content of chlorophyll a $(56.07 \mathrm{mg} / \mathrm{g})$ and total chlorophyll
\end{abstract}


$(61.35 \mathrm{mg} / \mathrm{g})$ were found in samples treated with hormonal medium, supplemented with $1.5 \mathrm{mg} / \mathrm{L}$ of BAP with $0.5 \mathrm{mg} / \mathrm{L}$ of NAA. The maximum number (3) and average length $(33.3 \mathrm{~mm})$ of roots were observed in samples treated with the hormone-free medium.

Keywords. explant, medicine, mercuric chloride, stress, tissue culture

Cresti, 1987 مقله

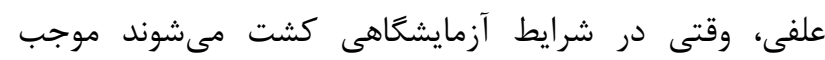

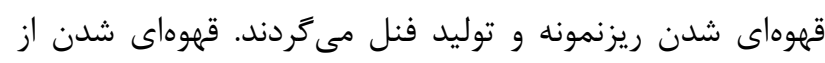

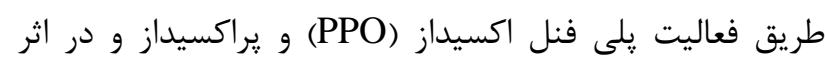

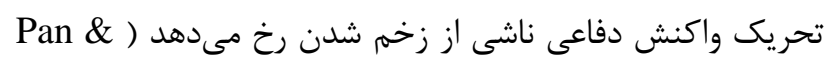

.(Staden, 1999

نوع ريزنمونه استفادهده در محيط كشت تاثير زيادى در تكثير

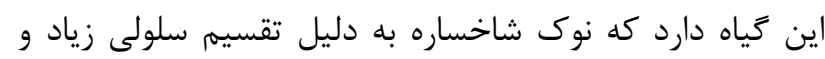

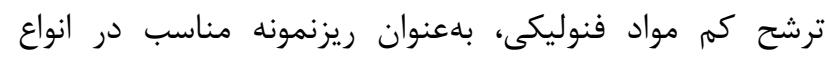

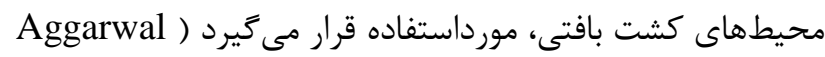
\& Barna., 2004; Liao et al., 2004; Hamid Oghli et al., 2005; Velcheva et al. 2005; Hashem Abadi \& (Kaviani, 2008; Kanwar et al., 2015

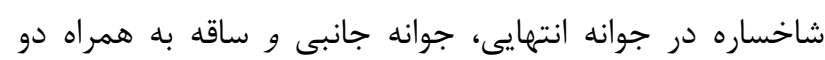
برك كنارى (Shamsian et al., 2016)، ياجوش ( Golchubian (et al., 2012

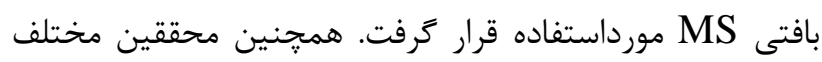

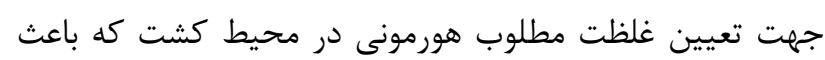

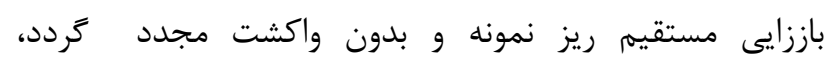
آزمايشات متفاوتى راطر احيى كردند. نتايج تحقيقى ( Baksha et

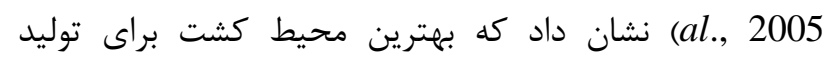

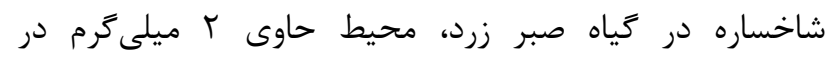

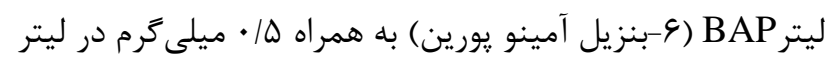
NAA

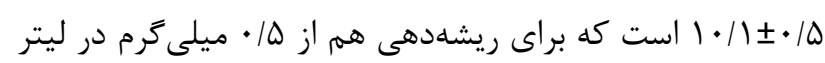

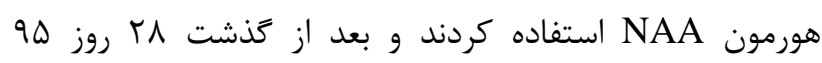

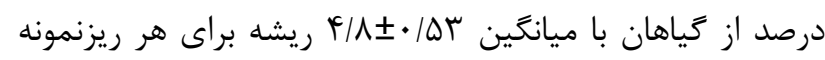

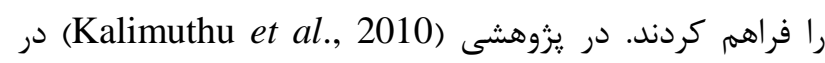

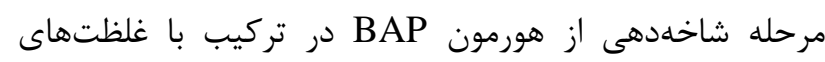

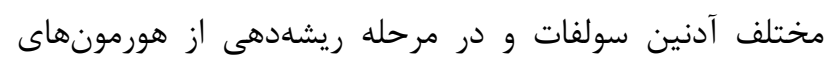

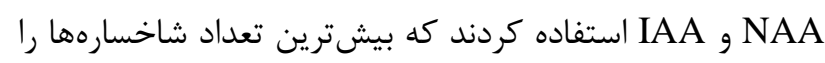

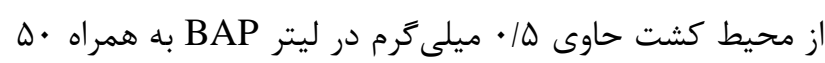
ميلى

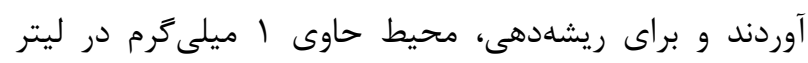

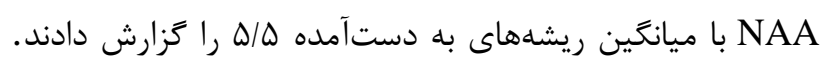

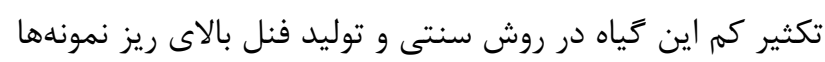
ارزش دارويى، تقاضاى بازار و سطح فراورى از مهمترين

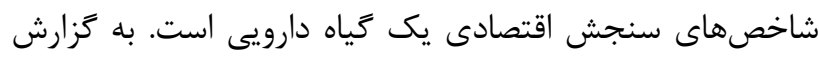

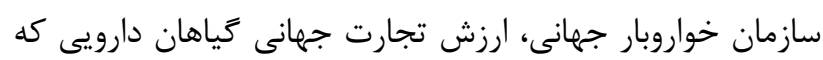

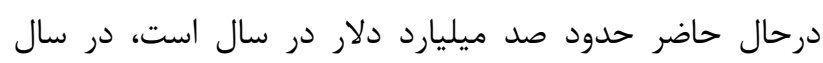

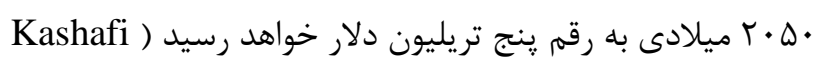

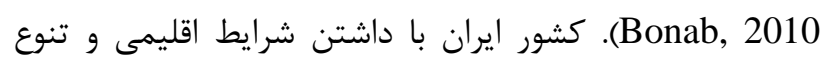

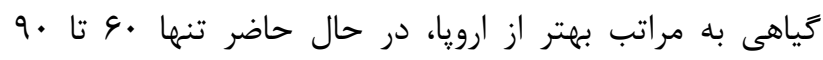

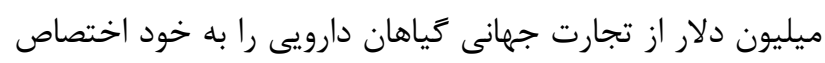

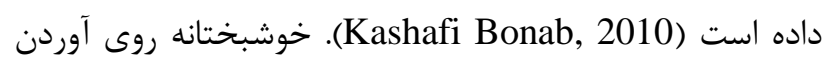

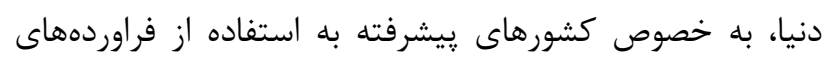

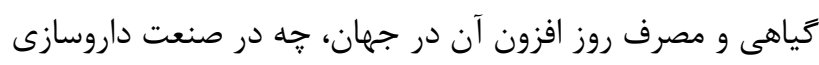

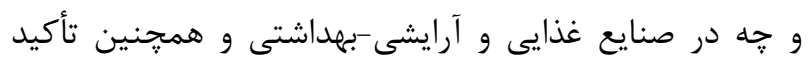
سازمان بهداشت جهانى درجايخزينى تدريجى مواد طبيعى بـ إنه جاى مواد شيميايى موجب شده تا كشورهاى مختلف جنان جهان

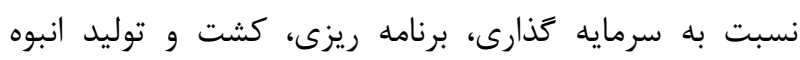

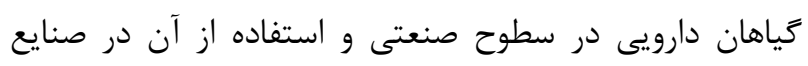

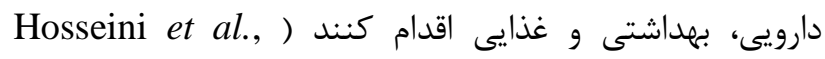
2008). يكى از مهمترين كياهان دارويى حال حاضر دنيا، كياه

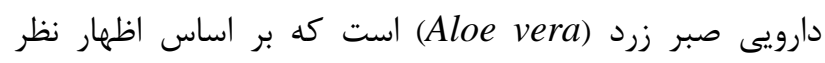
International Aloe Science Council (IASC)

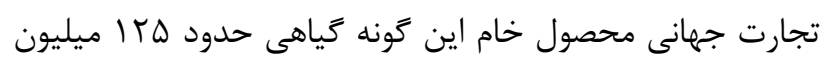

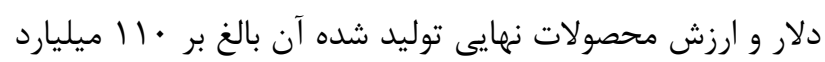
دلار است.

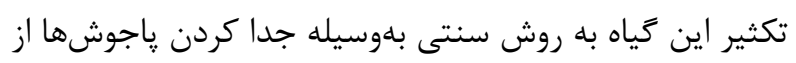

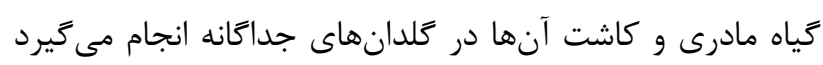

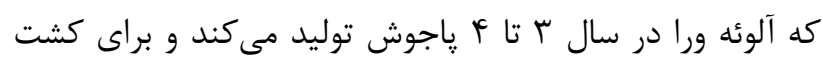

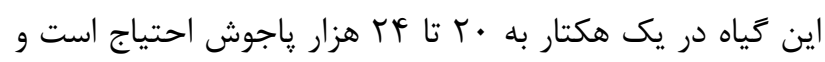

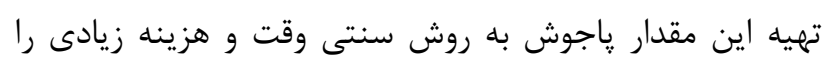

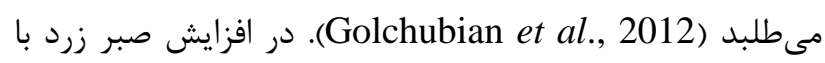

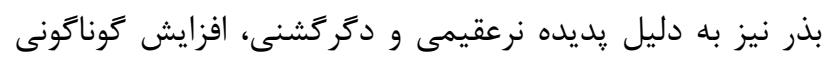

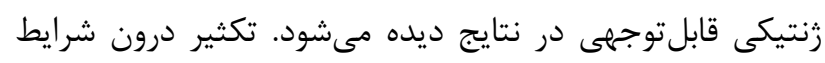

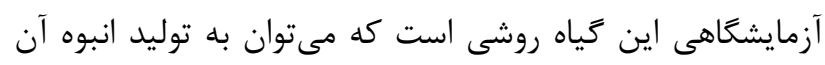

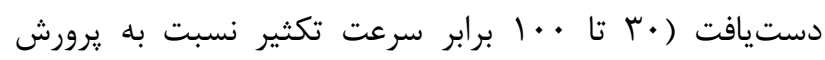

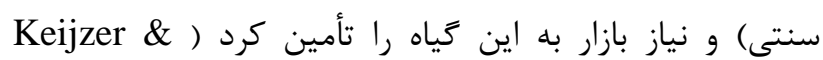


اندازهَيرى صفات ظاهرى و فيتوشيميايى

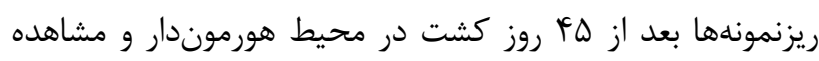
ريشه و ساقه مورد ارزيابى قرار گرفتند. صفات ظاهرى اندازهَيرى شده شامل درصد استقرار نمونهها در محيط كشت بافتى، تعداد ساقه و ريشه، طول ساقه و ريشه (با خطكش ميلىمترى)، تعداد

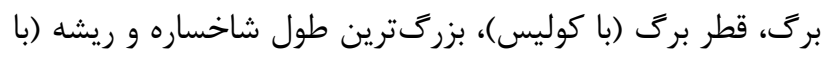

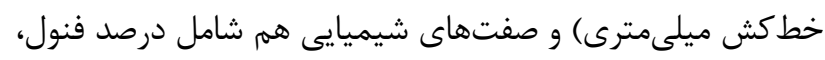
كلروفيل a، كلروفيل b، كلروفيل كل و كارتنوئيد (ميلى بود. براى سنجش درصد فنول، هر شرايط آزمايشعاهى كشت

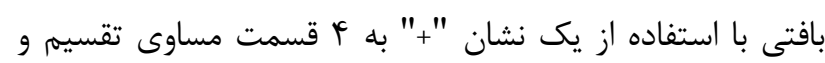

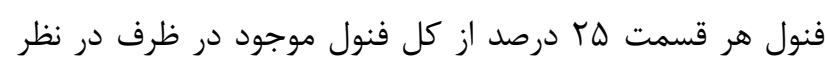
گرفته شد. براى اندازهزيرى صفات فيتوشيميايى، از هر تكرار

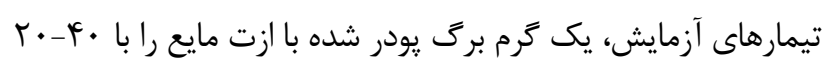

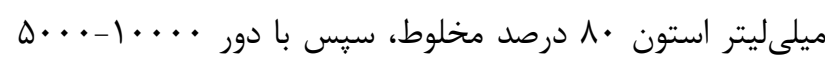
به مدت ه دقيقه سانتريفيوز زرديد. سيس قسمت بالايى محلول

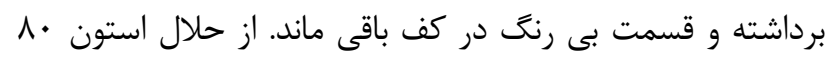
درصد براى كاليبره كردن دستخاه اسيكتوفتومتر استفاده شد و ورافى محتواى محلول بى رنت در طول موجهاى ل\& نانومتر به ترتيب براى سنجش مقدار كلروفيل a b و و كارتنوئيد قرائت كرديد.

دادههاى بلدستآمده از اندازهخيرىهاى صفات ظاهرى و و شيميايى به صورت ميانگين تكرارها I انحراف از ميانگين ارائه شدهاند. آناليز دادهها با استفاده از نرمافزار SAS و و مقايسه ميانگينها با آزمون LSD (حداقل تفاوت معنى دار) انجام شدند.

\section{نتنايج}

نتايج حاصل از روشهاى مختلف سترون كردن نشان داد كه

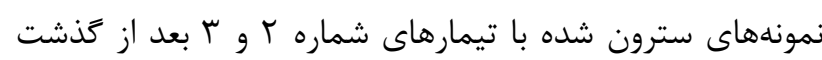

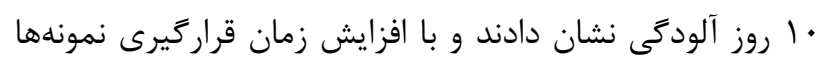

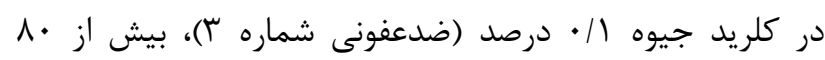
درصد نمونهها سوختكى نشان دادند. همجنين نمونههاى سترون

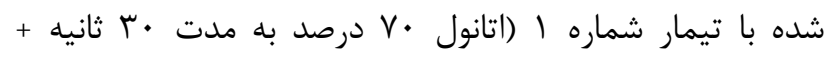

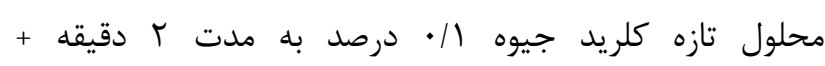
هييوكلريت سديم ها درصد ه دقيقه) داراى بيشترين درصد

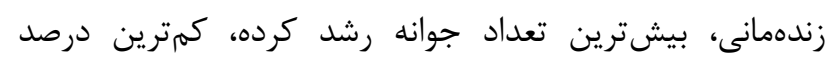
سوختخى و كمترين درصد آلودگى را داشتند (جدول () ).

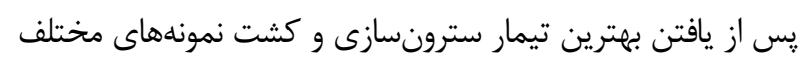

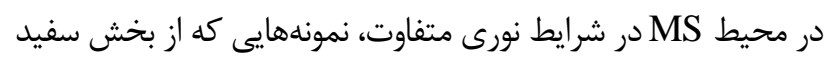
ياجوش گرفته بودند داراى درصد فنل كمترى بوده است (شكل ( )
در روش كشت بافتى از جمله مشكلات محدود كننده افزايش فراوان اين زياه محسوب مىشود. به همين منظور از جمله اهداف اين تحقيق شامل كنترل مواد فنوليكى در تكثير فراوان و

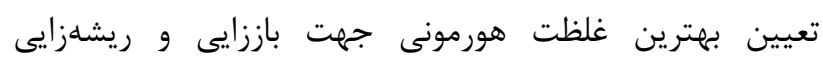
مستقيم و بدون واكشت بود.

مواد و روشها

جمع آورى نمونهها

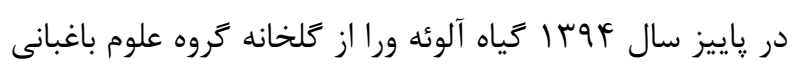

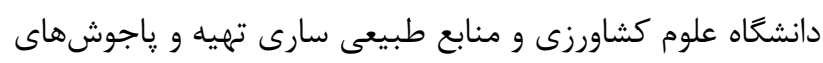
متفاوت از زياه مادرى جدا شدند.

\section{سترونسازى ريزنمونهها}

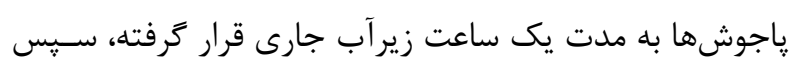

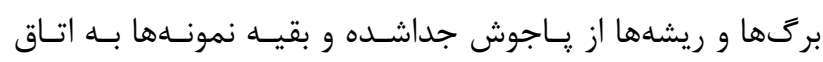

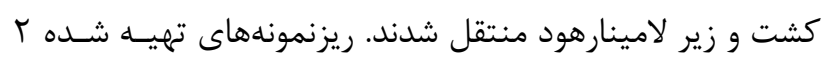
سانتىمترى به سه روش زير سترون شدند.

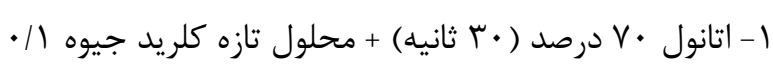
درصد (r دقيقه) + هييوكلريت سديم لا ال درصد ( له دقيقه)

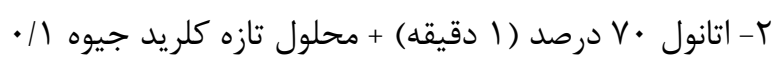

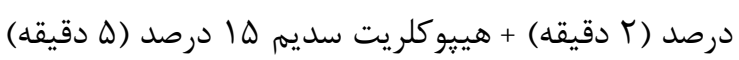

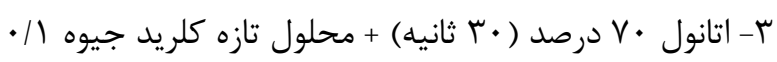

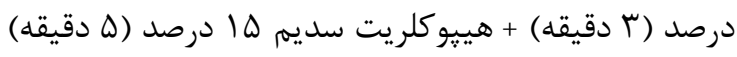
كشت ريزنمونهها در شرايط درون شرايط آزمايشگاهى

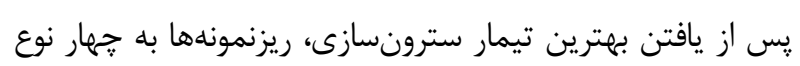

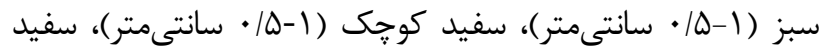

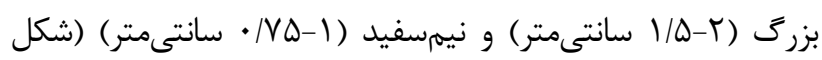
() تقسيم شدند و به محيط كشت MS بدون هورمون با ب شرايط نورى متفاوت تاريكى و روشنايى انتقال داده شدند.

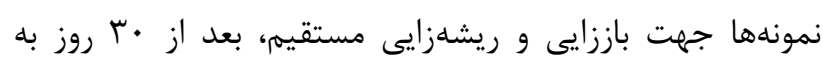

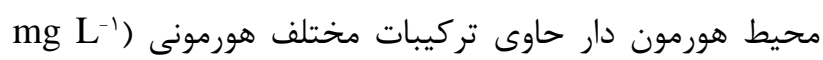

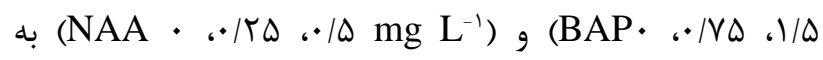
تنهايى و تركيب باهم، انتقال داده شدند. اين آزمايش بهصورت

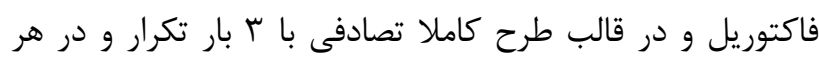
تكرار سه ريزنمونه انجام شد. شرايط آزمايشعاهى كشت بـ بافت بافت

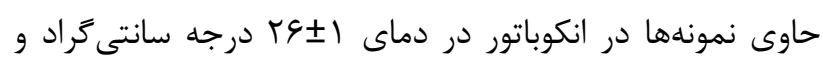

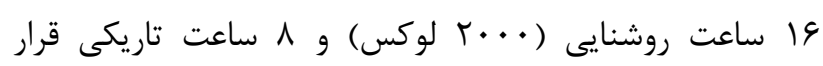

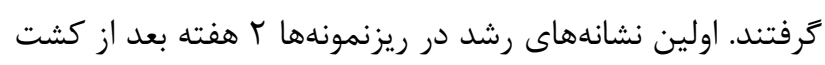

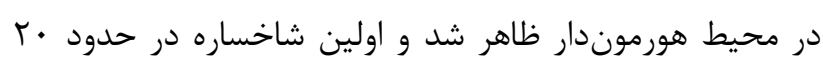

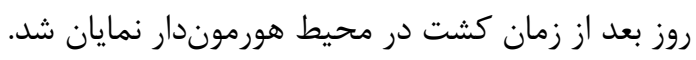


جدول ا- مقايسه ميانگين صفتهاى اندازميرى شده تحت تاثير تيمارهاى مختلف سترون.

Table 1. Means comparison of measured traits under different disinfection treatments.

\begin{tabular}{|c|c|c|c|c|}
\hline تعداد نمونه رشد كرده & درصد آلودگى & درصد سوختگى & درصد زندهمانى & تيمار ضدعفونى \\
\hline $.19 \mathrm{a}$ & $\cdot / \cdot \mathrm{b}$ & $r \Delta / \Delta \Delta \mathrm{C}$ & $v \Delta \mathrm{a}$ & 1 \\
\hline.$/ r b$ & $r \Delta \mathrm{a}$ & $\Delta \Delta \mathrm{b}$ & $90 \mathrm{c}$ & r \\
\hline.$/ \mu b$ & ז & $v \cdot a$ & $r \Delta \mathrm{c}$ & r \\
\hline
\end{tabular}

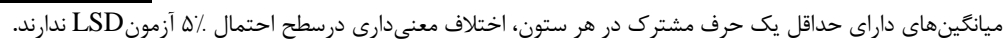

Means, in each column followed by at least on letter in common are not significantly different at 5\% probability level using LSD test.

جدول r- مقايسه ميانگين صفتهاى اندازهيرى شده تحت شرايط نور و نوع ريزنمونه.

Table 2. Means comparison of measured traits under light conditions and the type of explant.

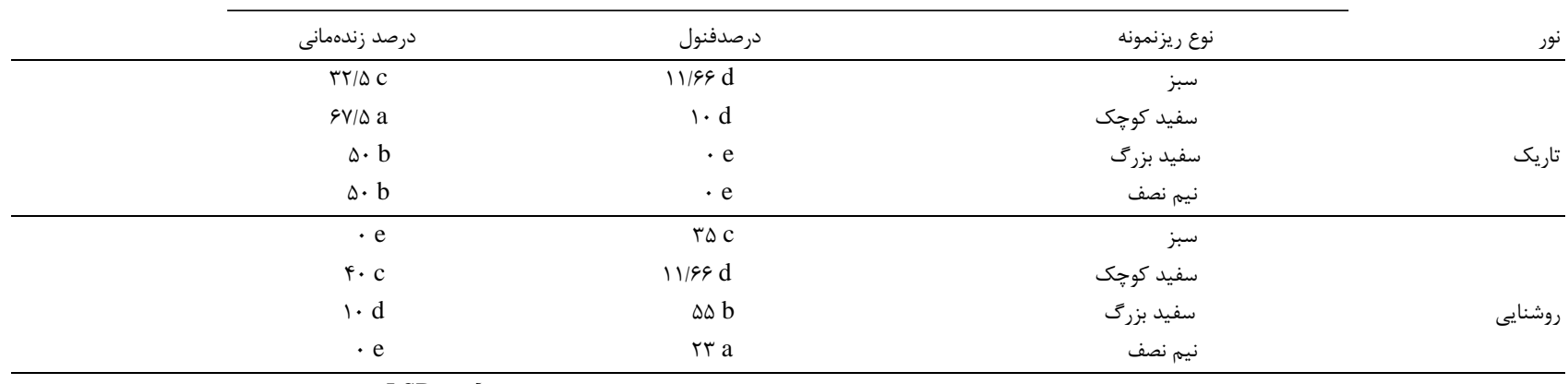

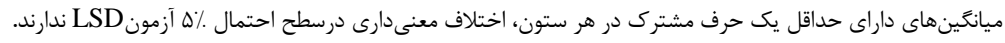

Means, in each column followed by at least on letter in common are not significantly different at 5\% probability level using LSD test.

جدول بـ - تجزيه واريانس تيمارهاى مختلف هورمونى بر روى صفتهاى آلوئه ورا در شرايط كشت در شرايط آزمايشعاهى.

Table 3. Analysis of variance of the effect of different hormonal treatments on Aloe vera properties.

\begin{tabular}{|c|c|c|c|c|c|c|c|c|c|c|c|c|}
\hline \multicolumn{11}{|c|}{ ميانكين مربعات } & \multirow[b]{2}{*}{ آزادى درجه } & \multirow[b]{2}{*}{ منابع تغييرات } \\
\hline كارتنوئيد & كلروفيل كل & كلروفيل bb & كلروفيل & قطر برى & استقرار & طول ريشه & طول ساقه & تعداد & تعداد ساقه & تعداد & & \\
\hline$r / \Delta^{* *}$ & 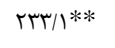 & $1 \% / q * *$ & $|r| / \Gamma^{* * *}$ & $\Delta / \varphi^{* * *}$ & $r \Delta \Delta / \cdot \varphi^{*} * *$ & rI/9人** & $111 / \Delta T^{*} * *$ & rq/४** & $1 / \Delta^{* *}$ & $\cdot / r \Delta * *$ & r & اكسين \\
\hline $9 / \Delta^{* * *}$ & $\mid V \in \mathbb{R} / 9 * *$ & $\Delta \mathrm{V} / /^{* *}$ & $\mid T \Delta N / \Delta^{* *}$ & $\varphi / 9 \mid * *$ & $r \cdot r \Lambda / r^{* * *}$ & 1 & $r \Delta \cdot / N^{* *}$ & q** & $\varphi / \cdot \Lambda^{* *}$ & $V / \Gamma \Delta * *$ & r & سايتوكنين \\
\hline$r / \cdot \wedge \omega^{* *}$ & $1 \pi 19 / V^{* *}$ & $1 \cdot 19 * *$ & $\mid r \cdot 9 / r^{* * *}$ & $1 \cdot / \Lambda * *$ & $\Delta F F / \Delta \& * *$ & FVF/IY** & ヘケฯ/ノ** & $9 / 1 V^{* *}$ & $1 / \cdot \wedge * *$ & $\gamma / \cdot 9 * *$ & r & اكسين*سايتوكنين \\
\hline$\Delta / r$ & $1 / V$ & $1 / 0$ & $\mid f / 49$ & $r / 9$ & $5 / \cdot 19$ & V/Ar & G/TT & $1 N / 9$ & $\mid \Delta / V \Lambda$ & $11 / 1$ & & $\mathrm{cV}$ \\
\hline Lr. & ./\%q & . & $\cdot / V$ & $\cdot 1 \cdot \Delta 1$ & $1 / .9$ &.$/ 9 r$ & $r / r q$ & $\cdot / l \Delta V$ & $.1 . r$ & $.1 .+9$ & ir & خطا \\
\hline
\end{tabular}

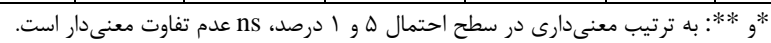

*, **: Significant at 5 and $1 \%$ possibility levels respectively; ns: non- significant

رشد طولى داشتند ولى اثرى از جوانه جانبى ديده نشد و بعد از هـ روز فاكتورهاى رويشى و فيزيولوزيكى مورد بررسى قرار گرفت. نتايج حاصل از تجزيه واريانس نشان داد كه در تمام تيمارها، صفتهاى مختلف ذكر شده در سطح احتمال ا درصد معنى دار بودند (جدول ؟). همجنين بررسىهاى آمارى بر اساس آزمون

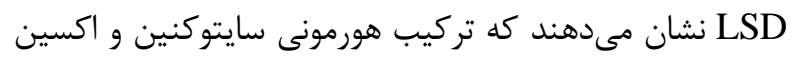
در محيط كشت بافتى نسبت به كاربرد بهتنهايى اين هورمونها

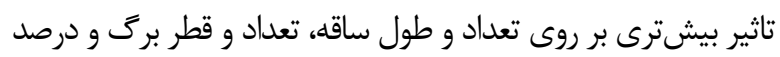

و هر جقدر سطح برش بيشتر شد رشد آن تحت تاثير قرار گرفت. به طورى كه نمونههايى كه از وسط نصف شده بودند داراى كمترين رشد و درصد زندهمانى بودند. در نمونههاى سفيد با حذف نور بهطور كامل از ترشح فنل جلوگيرى شد و رشد و ورى زندهمانى نمونهها افزايش يافت (جدول ب) با با توجه به به نتايج

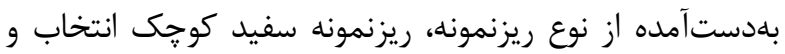

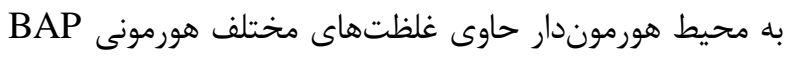

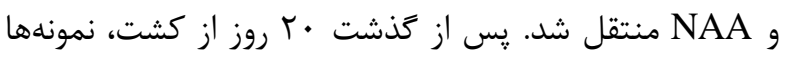


جدول F - مقايسه ميانگين اثر تيمارهاى مختلف هورمونى بر روى صفتهاى ظاهرى.

Table 4. Means comparison of the effect of different hormonal treatments on external traits.

\begin{tabular}{|c|c|c|c|c|c|c|c|}
\hline طول ريشه & تعداد ريشه & درصد استقرار & قطر برك(mm) & طول ساقه(mm) & تعداد بركى & تعداد ساقه & غلظت هورمون \\
\hline$r r / r a$ & ra & $v \cdot b$ & $r / q \mathrm{rd}$ & TN/GT C & $r / \Delta \mathrm{c}$ & $r b$ & NAA (0 mgl-1) + BAP (0 mgl-1) \\
\hline$\cdot \mathrm{f}$ & $\cdot d$ & $r \Delta d$ & $\cdot \mathrm{f}$ & $\cdot \mathrm{e}$ & $\cdot \mathrm{e}$ & $\cdot d$ & $\mathrm{NAA}(0 \mathrm{mgl}-1)+\mathrm{BAP}(0 / 75 \mathrm{mgl}-1)$ \\
\hline$\cdot f$ & $\cdot \mathrm{d}$ & $v \cdot b$ & $\mathrm{r} / \cdot \mathrm{rb}$ & $\mathrm{rr} / \mathrm{\Delta} \mathrm{b}$ & $\cdot / \Delta \mathrm{de}$ & Ic & NAA (0 mgl-1) + BAP (1/5 mgl-1) \\
\hline$r \cdot / 1 \Delta b$ & $1 / \pi r \mathrm{~b}$ & rVc & r/le & ro/frT d & $r / \Delta \mathrm{c}$ & $1 \mathrm{c}$ & NAA (0/25mgl-1) + BAP (0 mgl-1) \\
\hline $11 / 99 \mathrm{~d}$ & $1 \mathrm{c}$ & vra & $\mathrm{r} / \mathrm{A} \mathrm{a}$ & $F r / l \cdot V$ a & s/rra & $r / \Delta \mathrm{a}$ & NAA $(0 / 25 \mathrm{mgl}-1)+\mathrm{BAP}(0 / 75 \mathrm{mgl}-1)$ \\
\hline$\cdot f$ & $\cdot d$ & $r \mathrm{r} / \Delta \mathrm{d}$ & r/99 c & $r q / \Delta \Delta a$ & $r / \wedge r b$ & $1 \mathrm{c}$ & NAA $(0 / 25 \mathrm{mgl}-1)+$ BAP $(1 / 5 \mathrm{mgl}-1)$ \\
\hline $9 / \mathrm{Ve}$ & Ic & VT/Tra & $\mathrm{r} / \mathrm{Tre}$ & $r r / 19 d$ & Id & Ic & NAA (0/5mgl-1) + BAP (0 mgl-1) \\
\hline$r \Delta / r \mathrm{c}$ & $1 \mathrm{c}$ & « & $r / \Gamma \mathrm{c}$ & $r 1 / / b c$ & $r / \Delta \mathrm{c}$ & $1 \mathrm{c}$ & NAA $(0 / 5 \mathrm{mgl}-1)+\mathrm{BAP}(0 / 75 \mathrm{mgl}-1)$ \\
\hline . $\mathrm{f}$ & $\cdot \mathrm{d}$ & rie & $\cdot e$ & $\cdot e$ & $\cdot \mathrm{e}$ & ic & NAA (0/5mgl-1) + BAP (1/5mgl-1) \\
\hline
\end{tabular}

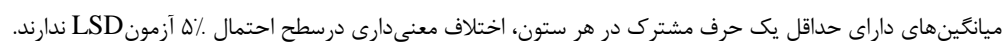

Means, in each column followed by at least on letter in common are not significantly different at 5\% probability level using LSD test

$$
\text { جدول هـ مقايسه ميانكين اثر تيمارهاى مختلف هورمونى بر روى صفتهاى بيوشيميايى. }
$$

Table 5. Means comparison of the effect of different hormonal treatments on biochemical properties traits.

\begin{tabular}{|c|c|c|c|c|}
\hline $\begin{array}{l}\text { كارتنوئيد } \\
\mathbf{m g} / \mathbf{g}\end{array}$ & $\begin{array}{c}\text { كلروفيل كل } \\
\text { mg/g }\end{array}$ & $\begin{array}{l}\text { b كلروفيل } \\
\text { mg/g }\end{array}$ & $\begin{array}{l}\text { a كلروفيل } \\
\text { mg/g }\end{array}$ & غلظت هورمون \\
\hline r/QT C & $01 / \mathrm{V} \cdot 9 \mathrm{c}$ & $0 / 499 \mathrm{c}$ & $r \& / 9 \mathrm{~V} \mathrm{C}$ & NAA (0 mgl-1) + BAP (0 mgl-1) \\
\hline $1 / \Delta / \mathrm{f}$ & $1 \cdot / r \mathrm{~h}$ & $\cdot / \Delta r \mathrm{~g}$ & $9 / \Delta \Delta r \mathrm{~h}$ & $\mathrm{NAA}(0 \mathrm{mgl}-1)+\mathrm{BAP}(0 / 75 \mathrm{mgl}-1)$ \\
\hline$r / \varphi_{\Delta} \mathrm{e}$ & $r \cdot / l \cdot r f$ & r/q $\mathrm{e}$ & re/ref & NAA (0 mgl-1) + BAP (1/5 mgl-1) \\
\hline $\mathrm{I} / \mathrm{vr} \mathrm{f}$ & $r \cdot / \kappa \Delta d$ & $r / / 99 \mathrm{f}$ & ri/rre & NAA (0/25mgl-1) + BAP (0 mgl-1) \\
\hline$f / \Lambda)$ a & $r \cdot / 1 \mathrm{~g}$ & $9 / r \mid 9 \mathrm{a}$ & IV/arg & $\begin{array}{c}\text { NAA }(0 / 25 \mathrm{mgl}-1)+\mathrm{BAP}(0 / 75 \mathrm{mgl}- \\
1)\end{array}$ \\
\hline$r / 9 \Delta \mathrm{b}$ & $\varepsilon_{1 / r \Delta \mathrm{a}}$ & $r / 9 \Delta d$ & $\Delta \varepsilon / \cdot \vee \mathrm{a}$ & NAA $(0 / 25 \mathrm{mgl}-1)+\mathrm{BAP}(1 / 5 \mathrm{mgl}-1)$ \\
\hline$r / V \Delta S C$ & $\Delta 9 / v \& b$ & $q / \cdot \Delta r \mathrm{~b}$ & $\Delta F / \cdot r b$ & NAA (0/5mgl-1) + BAP (0 mgl-1) \\
\hline t/VGT d & rV/qge & r/grte & rr/v d & NAA $(0 / 5 \mathrm{mgl}-1)+\mathrm{BAP}(0 / 75 \mathrm{mgl}-1)$ \\
\hline $1 / 9 \wedge \mathrm{f}$ & $9 / \mathrm{V \Delta S} \mathrm{h}$ & $\cdot 109 \mathrm{~g}$ & $9 / / r \varepsilon h$ & NAA $(0 / 5 \mathrm{mgl}-1)+\mathrm{BAP}(1 / 5 \mathrm{mgl}-1)$ \\
\hline
\end{tabular}

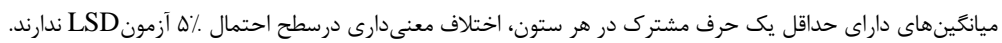

Means, in each column followed by at least on letter in common are not significantly at 5\% probability level using LSD test

اين گونه به نظر مىرسد زمانى كه از BAP و NAA بهصورت تركيبى در محيط كشت استفاده مىشود نسبت به زمانى كه هر

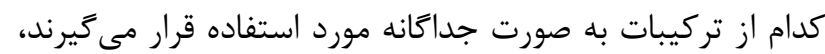
مقدار كلروفيلها و كارتنوئيد موجود در نمونهها افزايش بيشترى را نشان مىدهد. به طورى كه مقدار كلروفيل a ) a

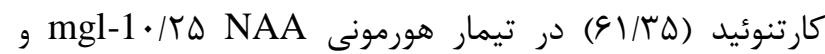

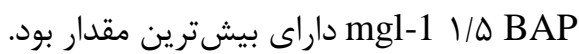

\section{بحث}

بخش اول اين تحقيق به دنبال يافتن يروتكل ضدعفونى

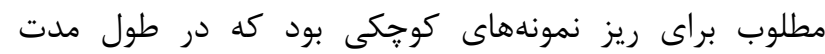

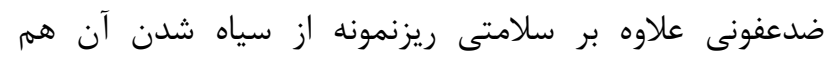

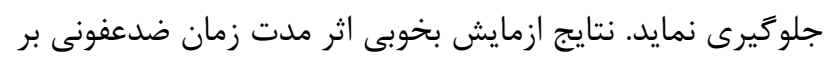

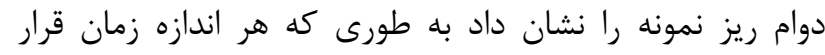

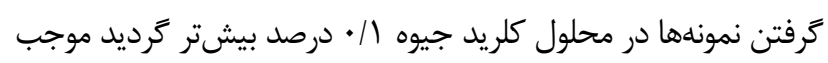

استقرار ريزنمونه در محيط كشت بافتى دارد بلطورىكه تركيب

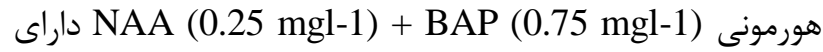

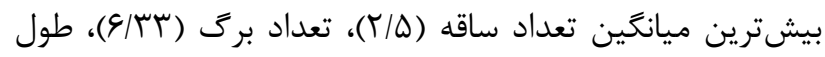

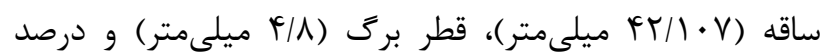
استقرار (سT درصد) بود (جدول ₹ا). در مرحله ريشهدهى بهترين نتيجه در محيط كشت بدون هورمون با ميانخين ب ريشه و ميانكين طول سر/س مس ميلىمتر حاصل شد كه نمونهها ريشههاى نازكى را ايجاد نمودند و ضعيفترين نتيجه از محيط كشت حاوى

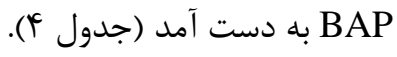

تجزياهوتحليل دادههاى حاصل از صفتهاى شيميايى حاكى از آن است كه مقدار كلروفيل b و كارتنوئيدها با افزايش تعداد بركها افزايش ريداكرده به طورى كه در محيط كشت هورمونى

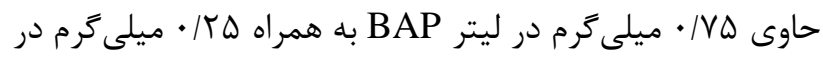

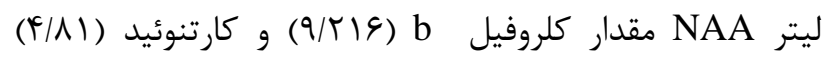
نسبت به شاهد و ساير تيمارها افزايش •• لدرصدى را نشان داد. 

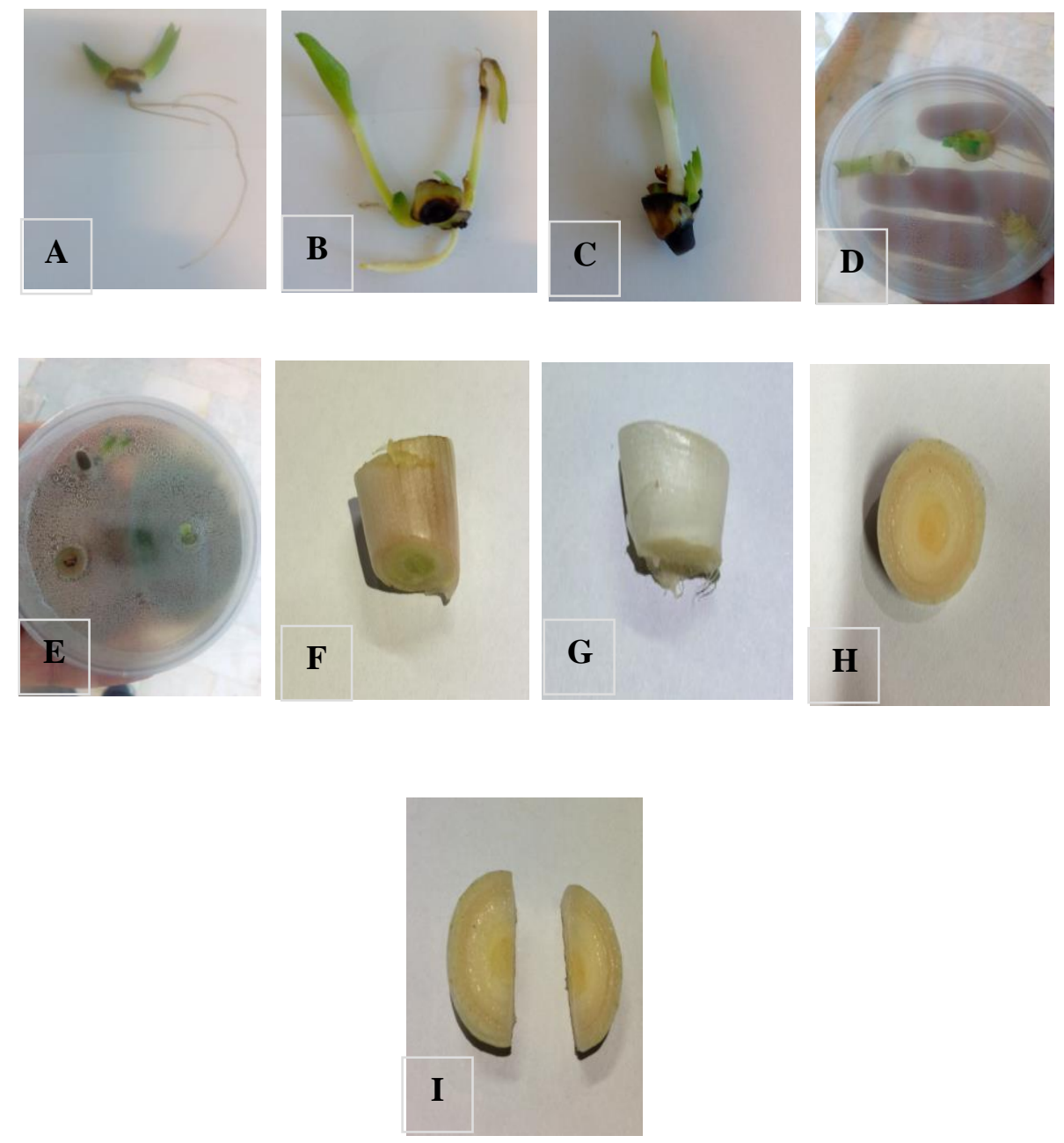

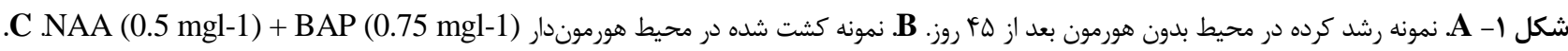

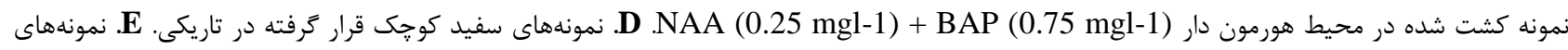

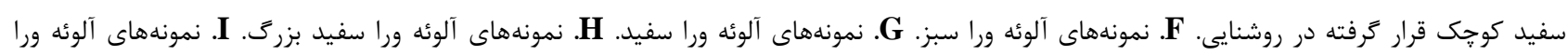

Fig. 1. A. Grown specimens in a hormone-free medium after 45 days. B. Samples cultured in NAA $(0.5 \mathrm{mg}-1)+$ BAP (0.75 mg / L) hormone medium. C. Sample cultured in NAA (0.25 mgl-1) + BAP (0.75 mgl-1) and BAP (0.75 mgl-1). D. Small white specimens in the dark. E. Small white specimens in light. F. Aloe vera green samples. G. Aloe vera white Samples. H. White Aloe vera Samples. I. Aloe vera half-whitish specimens.

قارجكش كاربندازيم ا درصد به مدت •r دقيقه، الكل •V درصد

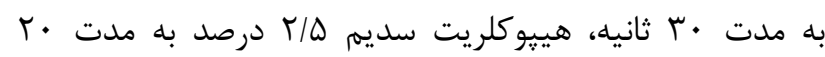
دقيقه و كلريد جيوه || • درصد به مدت · • آدقيقه براى استريل

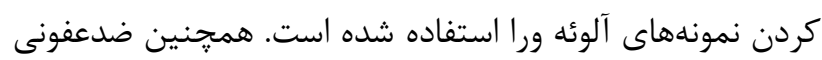

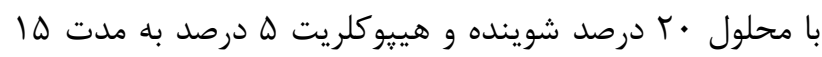
دقيقه اعلام شده است (Hamid Oghli et al., 2005). در يزوهش ديخرى از كاربندازيم I درصد به مدت · r دقيقه و كلريد جيوه / / • درصد به مدت ه ه تا V دقيقه استفاده كردند

(Saggoo \& Kaur, 2010)

هدف بخش دوم آزمايش جلوگيرى از قهوهاى شدن ريز نمونهها در طول باززايى مستقيم ريز نمونه بود. واكنش قهوهاى شدن
سوختگى نمونهها و هر قدر زمان قرار گرفتن نمونهها در الكل بيشتر مىشد مرگ نمونهها و زرد شدن نمونهها را بـ همراه

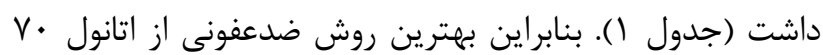

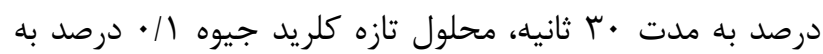

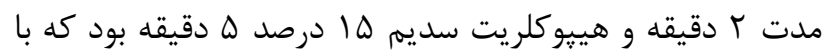
نتايج برخى يروهشها (Shamsian et al., 2016) مبنى بر اينكه كلريد جيوه / / • درصد مؤثرترين تيمار ضدعفونى در كنترل آلودگى و زندهمانى ريزنمونههاى آلوئه ورا است ( \&aggoo \&

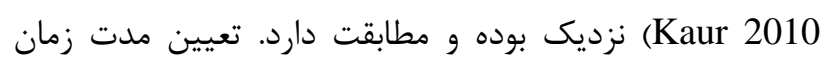
تيمار ضدعفونى كننده در تحقيقات مختلف هم مورد توجه قرار

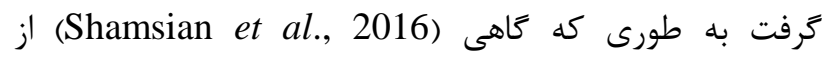


2001; Aggarwal \& Barna 2004; Liao et al., 2004; (Baksha et al., 2005; Hashem Abadi \& Kaviani, 2008 مبنى بر اين كه BA تنها براى القاى ساقه مناسب است مغايرت

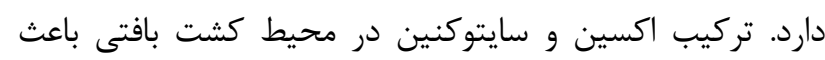

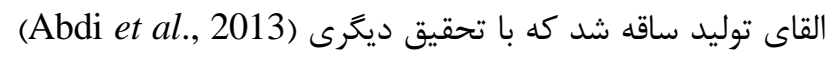

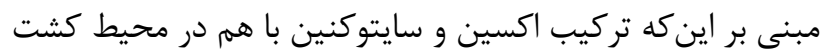

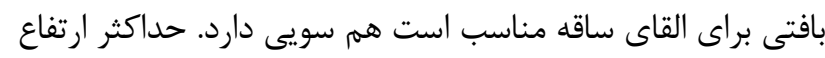

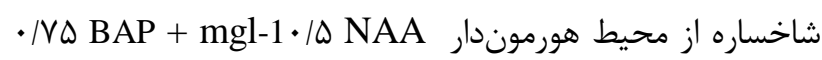

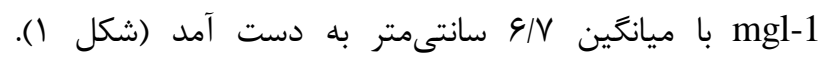
بررسىها نشان مى دهد (Abdi et al., 2013) كه با افزايش غلظت NAA در محيط كشت ريشههاى كوتاه و ضخيمى توليد

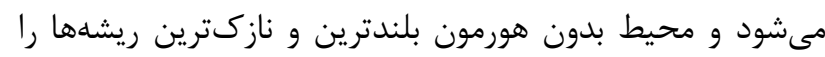

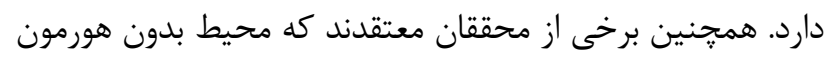

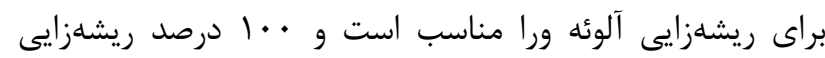

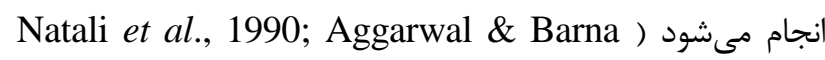
(2004, Barna \& Wakhlu 1994 حاضر نيز منطبق است درحالى كه برخى ديكر از محققان

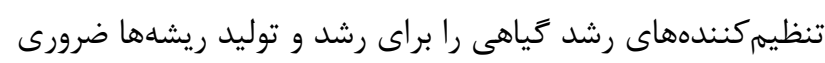

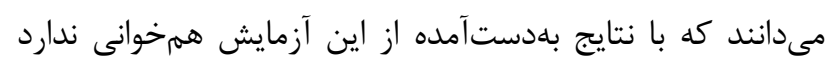
Abrie \& Staden, 2001; Meyer \& Staden, 1991; ) Velcheva et al., 2005; Baksha et al., 2005; Ahmed et .(al., 2007; Golchubian et al., 2012

\section{نتيجه كَيرى}

به طور كلى نتايج نشان داد كه نمونههاى سفيد به دست آمده

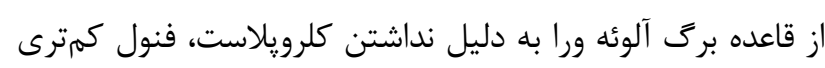

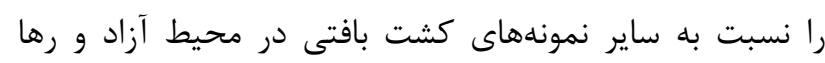

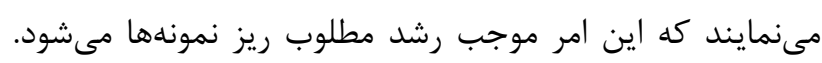

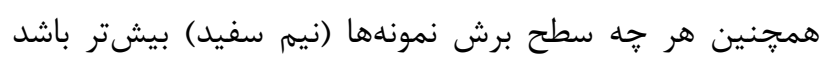

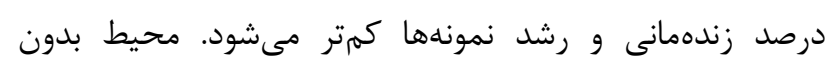

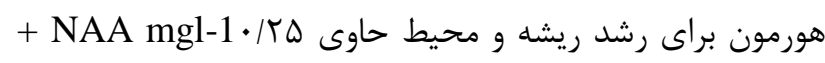

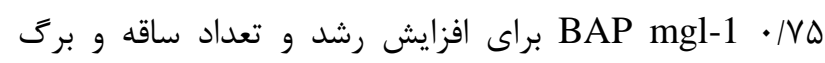

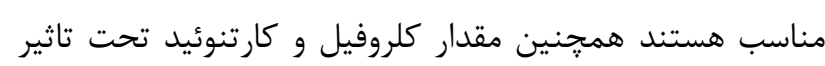

$$
\text { تيمار هورمونهاى محيط كشت قرار مى كيرد. }
$$

\section{سياسگَزارى}

بدينوسيله از مهندس رقيه اصغرزاده مسئول آزمايشكاه كشت

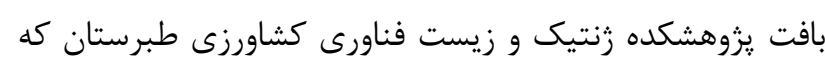

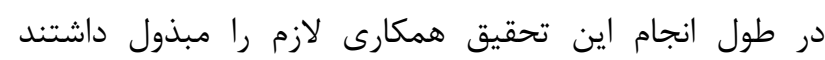
قدردانى مىشود.
محيط و توليد فنول توسط آنزيم يلى فنول اكسيداز صورت

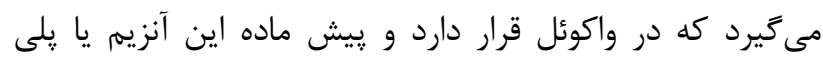

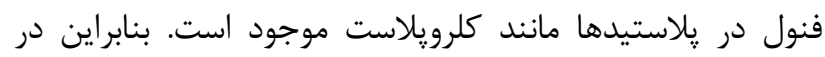

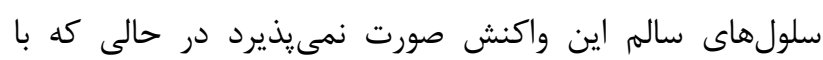

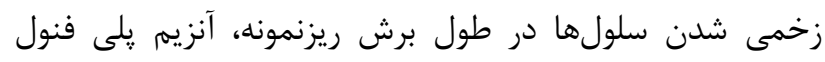

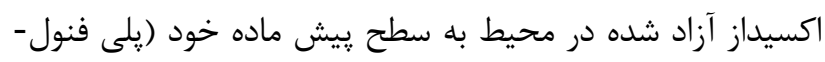
ها) مى جسبد و باعث قهوهاى شدن محيط و توليد فنول مى إشوند.

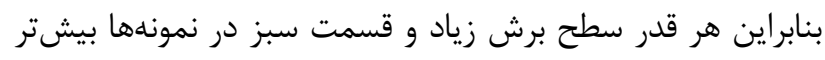

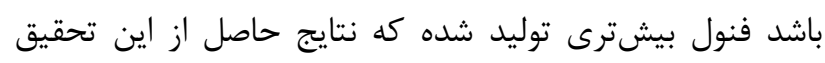

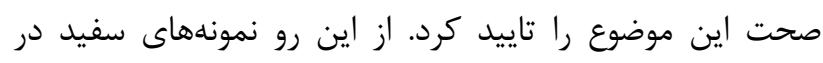
تاريكى به دليل نداشتن كلرويلاست نسبت به نيه نيم سفيد و ور سبز

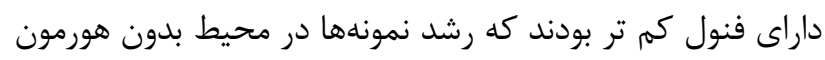

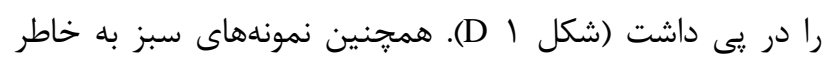

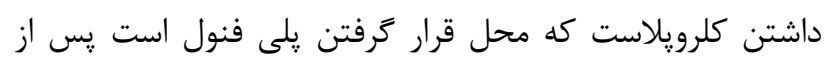

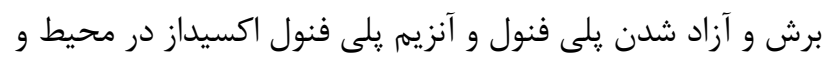

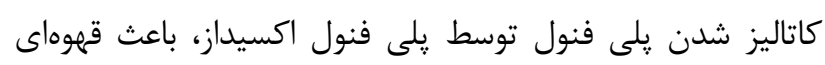

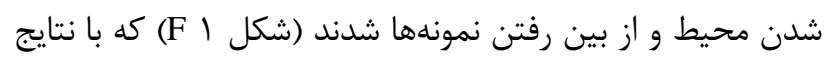

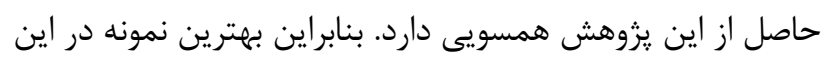

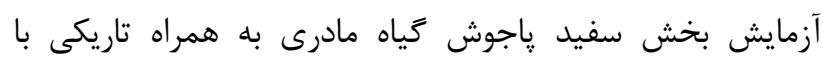

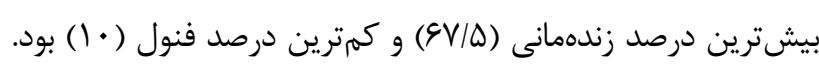

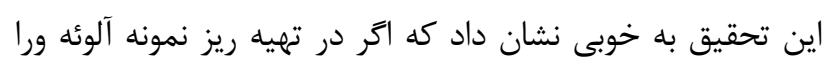

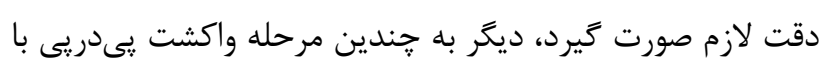
هزينه بالاى محيط كشت نيست. به طورى كه بر بروهشكران

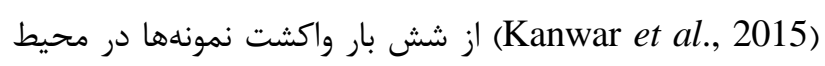

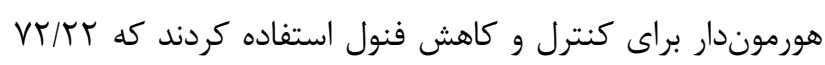

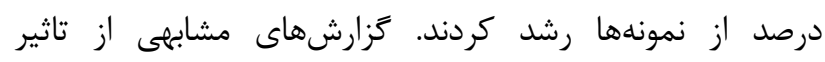

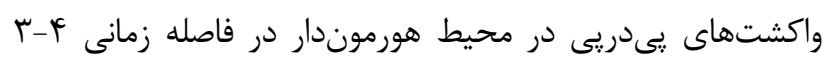

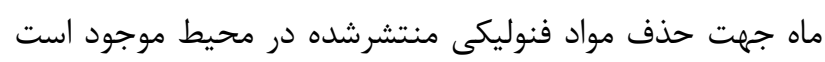
(Golchubian et al., 2012 و Hamid Oghli et al., 2005) در تحقيق ديخرى از ب گرم زغال فعال در محيط هورموندار براى

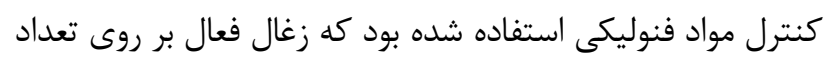

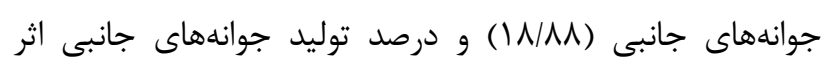

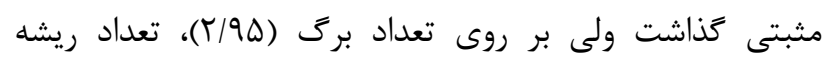

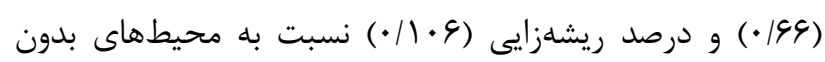

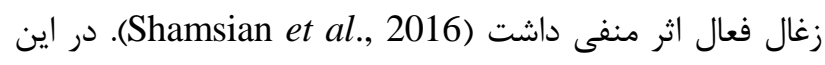

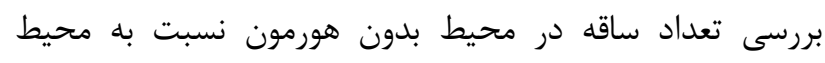

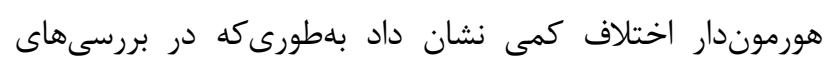

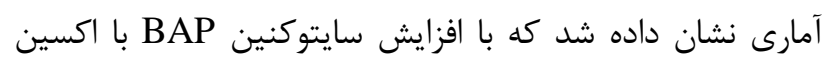
صفر در محيط كشت بافتى تعداد ساقه كمترى توليد شد (جدول

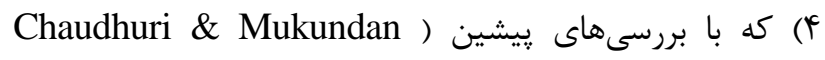




\section{REFERENCES}

Abdi, Gh., Hedayat, M. and Modarresi, M. 2013. In vitro micropropagation Aloe vera-impact of plant growth regulators, media and types of explant. - J. Biol.. Environ. Sci. 7: 19- 24.

Abrie, A.L and Staden, J.V. 2001. Micropropagation of the endangered Aloe polyphylla. - Plant Growth Regul. 33: 19- 23.

Aggarwal, D., and Barna, KS. 2004. Tissue culture propagation of elite plant of Aloe vera Linn. - J. Plant Biochem. Biotech. 13: 77-79.

Ahmed, S., Kabir, A.H., Ahmed, M.B., Razvy, M.A. and Ganesan, S. 2007. Development of rapid micropropagation method of Aloe vera. Lizvorniznanstveni Rad. 24: 121-128.

Baksha, R., Jahan, M.A.A., Khatun, R. and Munshi, J.L. 2005. Micropropagation of Aloe barbadensis Mill. throughin vitro culture of shoot tip explants. - Plant Tiss. Cul. Biotech. 15: 121-126.

Barna, K.S. and Wakhlu, A.K. 1994. Whole plant regeneration of Cicer arietium from callus culture via organogenesis. - J. Plant Cell Rep. 13: 510-513.

Chaudhuri, S. and Mukundan, U. 2001. Aloe vera L. Micro propagation and characterization of its gel. - J. Phytomorph. 51: 155-157.

Golchubian, S., Ranjbar, Gh. and Kazemi Tabar, S.K. 2012. In vitro micro propagation of Aloe vera $\mathrm{L}$. - J. Plant Biol. 7: 71-78.

Hamid Oghli, Y., Fatahi Moghaddam, C. and Fotouhi Qazvini, R. 2005. In vitro fertilization of the Aloe barbadensis Miller. - Iranian J. Agri. Sci. 4: 903-909.

Hashem Abadi, D. and Kaviani, B. 2008. Rapid micropropagation of Aloe vera L. via shoot multiplication. - Afri. J. Biotech. 4: 1899-1902.

Hosseini, S.A., Abrasaghi, Gh. and Hosseini, S.A. 2008. Medicinal plants of Golestan province. - Iranian J. Medi. Aroma. Plant 24: 472-498.

Kalimuthu, K., Vijayakumar, S., Senthilkumar, R.R. and Sureshkumar, M. 2010. Micropropagation of Aloe vera Linn., a medicinal plant. - J. Bio. Biochem. 6: 405-410.

Kanwar, K., Devi, V., Sharma, S., Soni, M. and Sharma, D. 2015. Effect of physiological age and growth regulators on micropropagation of Aloe vera followed by genetic stability assessment. - Natl. Acad. Sci. Lett. 38: 29-35.

Kashafi Bonab, A.S. 2010. Comparative advantage of economic growth and trade of medicinal plants in Iran and its value in global markets. - Commerci. Survey 44: 67-78.

Keijzer, C. and Cresti, M. 1987. A comparison of anther tissue development in male sterile Aloe vera and male fertile Aloe ciliaris. - Annal. Bot. 59: 533-542.

Liao, Z., Chen,M., Tan, F., Sun, X. and Tang, K. 2004. Micro propagation of endangered Chinese aloe. - J. Plant. Cell. Tiss. Org. Cul. 76: 83-86.

Meyer, H.J. and Staden, J.V. 1991. Rapid in vitro propagation of Aloe barbadensis Mill. - J. Plant Cell. Tiss. Org. Cul. 26: 167-171.

Natali, L., Sanchez, I.C. and Cavallini, A. 1990. In vitro culture of Aloe barbadensis Mill: Micropropagation from vegetative meristems. - J. Plant Cell Tiss. Org. Cul. 20: 71-74.

Pan, M.J. and Staden, J.V. 1999 Effect of activated charcoal, autoclaving and culture media on sucrose hydrolysis. - J. Plant Growth Regul. 29: 135-141.

Saggoo, M.I. and Kaur, R. 2010. Studies in North Indian Aloe vera: callus induction and regeneration of plantlets. - Archi. Appli. Sci. Res. 2: 241-245.

Shamsian, S., Omidi, M. and Torabi, C. 2016 .effect of growth regulators and active charcoal on the proliferation of Aloe vera L. in vitro. - Iranian J. Medicin. Aroma. Plant 32: 281-289.

Velcheva, M., Faltin, Z., Vandi, A., Eshdat, Y. and Perl, A. 2005. Regeneration of Aloe arborescens via organogenesis from young in florescence. - J. Plant Cell Tiss. Org. Cul. 83: 293- 301.

How to cite this article:

Saedi, A., Moradi, H. and Karimi, M. 2020. The effect of growth regulators and light on the phenolic content and in vitro regeneration of Aloe vera. - Nova Biol. Reperta 6: 487-494. (In Persian)

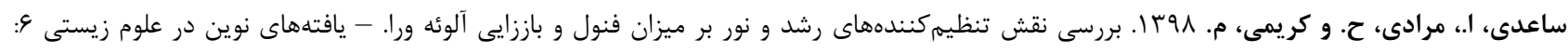

